Author version: Scientometrics, vol.92; 2012; 609-619

\title{
A Deductive Approach to Select or Rank Journals in Multifaceted Subject, Oceanography
}

\author{
Satya Ranjan Sahu ${ }^{1 *}$, Krushna Chandra Panda ${ }^{2}$ \\ 1 National Institute of Oceanography (CSIR), Dona Paula, Goa, India - 403004 \\ 2 Department of Library \& Information Science, Sambalpur University, Jyoti Vihar, Sambalpur, \\ Odisha, India - 768019
}

*Corresponding author:

Phone: $+91-(0) 832-2450370$

Fax: $+91-(0) 832-2450601$

Email: satya@nio.org

\begin{abstract}
:
Whether singleton approach (citation analysis of identified source journals) used by Gross \& Gross (1927) or differential approach (citation analysis of articles in specific subject field) applied by Bradford (1934) suitable to select or rank journals in multifaceted subject - 'Oceanography' is presented. This study discusses both the approaches analyzing citations of published literature in oceanography from thirty countries. The ranking correlation of journals showed better positive correlation (lowest $\rho=0.662$ for 2005-09 to highest $\rho=0.817$ for 1995-99) when top ranked journals from the list generated complying Gross \& Gross approach were correlated with same journal titles of the list generated complying Bradford approach than the other way (lowest $\rho=0.588$ for 2005-09 to highest $\rho=0.726$ for 1990-94). Both the approaches matched similar number of journals to county-wise lists and give unbiased choice in preferring a ranking list. The journals distribution graphs showed typical Bradford-Leimkuhler curves in both the approaches for all the datasets. But the groos droop appears comparatively early with shorter straight line in Gross \& Gross approach. The high clustering of literature to limited number of journals is a disadvantage in multifaceted subject. So the differential approach used by Bradford is being considered suitable for multifaceted subject like, 'Oceanography'.

Keywords: Ranking journals; Ranking correlation; Citation analysis; Information process; Bradford distribution
\end{abstract}




\section{Introduction}

In last few years, an increase in globalization of scientific research has been experienced. The scientific literature which was growing steadily couple of decades earlier has shot up since then (Robert et al. 2010; Mabe 2003). The technological advancement coupled with the increased number of scientific activities has become a driving force in publication of new primary and secondary sources. The study of this growth of literature produce by scientific community substantially helps in understanding the information processes at a given institute, country or subject level (Tapaswi \& Sainekar 1991). In scientific literature, references cited are very important element which substantiate the scientific writing and align the knowledge of the concerned domain. It is an established fact that, citation analysis is very significant for theoretical and practical reasons such as to describe the distributions, to evaluate the available resources, etc (Bonitz 1990). Each time a citation analysis is carried out to identify or to rank important sources in a given subject, it has benefited both theoreticians and practitioners in planning and designing of information systems.

The result of citation analysis initiative of Gross \& Gross (1927) from single volume of "The Journal of the American Chemical Society" helped in establishing a simple methodology to rank the journals. Subsequent studies in other field of science and technology have considerably advanced the citation research. One such important study of literature scattering is Bradford distribution. Bradford (1934) found that a limited number of journals provide most number of articles. It is interesting to notice that, Gross \& Gross had taken singleton approach (identified the source journal) whereas Bradford's differential approach (articles in the bibliographies of specific subject field) to account/rank the core journals. Both these methods make sense in the journal selection/ranking process to a specific subject field such as Chemistry (Gross \& Gross 1927); Mathematics (Allen 1929); Electrical Engineering (McNeely \& Crosno 1930); Geology (Gross \& Woodford 1931); Applied Geophysics and Lubrication (Bradford 1934), etc. But the suitability of either of the two approaches in a multifaceted subject like, 'Oceanography' (which deals with Earth Sciences, Chemical Sciences, Physical Sciences, Biological Sciences and Engineering purely or interdisciplinary way) remains to be debated.

There are a couple of such studies which are foremost in oceanography and contrary in their approach. In one such study, 21 core journals selected from a list were analyzed to prepare the ranking list (Fuseler-McDowell 1987). The selection of comparatively high number of journals seems to justify the method for multidisciplinary subject, but fails to confirm its suitability. The other study which considered the published literature in oceanography at national level (Tapaswi \& Maheswarapa 1999) is too in its approach justifies the Bradford method in getting a list of ranked 
journals, but shows a negative correlation with previous study (Fuseler-McDowell 1987). To investigate the right methodology in getting journals ranking in multifaceted subject like, 'Oceanography', both the approaches in a deductive manner have been studied in this paper so as to avoid the risk of a mismatch.

In this article, journals have been analyzed cited by oceanographers from thirty countries during 1990 to 2009 in their respective contributions. To unmask the degree of consistent in distribution of literature or ranking of journals, firstly a thorough check has been made to unfold whether the journals cited in different contributions follow Bradford's distribution and the list of journals to which most oceanographic literature have clustered (ranking list), secondly the citations of selected core journals were analyzed which are noticed in the nucleus zone and subsequent zones of first analysis, and lastly the ranking correlation between both the ranking lists (to reach deductively the better approach to select core journals in multi-interdisciplinary subject like 'Oceanography') were also studied at length.

\section{Methodology}

More than 150 countries are having coastline (https:/www.cia.gov/library/publications/the-worldfactbook/fields/2060.html). Selecting sample countries to analyze oceanographic literature was very much crucial. Coastline has its importance to a country from climatic, geographic, economic and strategic point of view and research activities aligned on these. Keeping these factors in mind, thirty countries from different continents (Fig. 1) were selected by ranking the average of ranks of coastline, gross domestic product (GDP) and publications. But preference was given to the countries those have better publications or distinct geographic location. Most of these countries are contributing literature to ASFA (Aquatic Science and Fisheries Abstract - a cooperative bibliographic database and is comprehensive) database.

Bibliographic records in the field of "Oceanography (also known as Marine Sciences)" were downloaded from the ASFA database for all the countries covering the period 1990-2009. A database was created with the downloaded records and analyzed to identify the major institutes in a country which contribute to oceanographic literature. ASFA database lacks the cited reference field but identified institutes were helpful in downloading oceanographic records (interdisciplinary in nature) from Web of Science (WOS) databases for citation. Another database was created after standardizing the 50,289 records downloaded from WOS in desired format. The authors of this paper credited an article to a country based on the affiliation of first author as it helped the authors in avoiding duplication. 
Ranking lists of serials were generated by citation analysis of all the records in the database for all the thirty countries combined and separately for four different times span (five year each). Cumulative number and percentage of articles against the natural logarithmic value of journals rank lists arranged in the order of decreasing productivity were plotted to get Bradford distribution. The authors observed that there are not more than 11 journals in the nucleus zone of the Bradford distribution (Fig. 2a \& 2b) for the combined analysis of thirty countries and all the journals in the nucleus zone are not pure Oceanographic in nature (Table 1). Based on the above observation, 11 pure Oceanography journals (common to all the time period) (Gross \& Gross, 1927) were selected from nucleus $\left(1^{\text {st }}\right)$ zone (5-11 journals) and subsequent zones of the curve for citation analysis. As before, once again the rank lists of serials were generated by citation analysis of 48953 records downloaded from WOS for these eleven journals. Then we correlate the ranks of journal titles in the lists generated from citation analysis of oceanographic articles independent of journals (Bradford 1934) with the rank lists generated from citation analysis of records of 11 core journals (Gross \& Gross 1927).

\section{Result and Discussion}

\section{Growth of the Subject}

The rate of change in mean number of references per article over time (Fig. 3) indicates that there is increasingly availability of citable material and a steady growth in field of Marine Sciences (Vinkler 1996; Seglen 1997). Around $80 \%$ of these citable materials are serials (Table 2) irrespective of time period and affirms pervious finding of Tapaswi \& Maheswarapa (1999). The table also shows that the large numbers of serial articles are distributed in less number of sources and few non-serial articles in more number of sources. This skewness of distribution has increased from the period of 1990-94 through 2005-09. It is due to some serials started to establish themselves in the field of Marine Sciences and discipline- specific serials started to publish.

\section{Journal Distribution and Ranking}

As it is discussed in the section 2 (methodology), Fig. 2a \& 2b show a typical Bradford -Leimkuhler curve for all the records analyzed irrespective of journal titles. When the serials were divided into a nucleus and two successive zones as per Bradford's Law of Scattering, it is found that, the nucleus consists of 5-11 journals in zone-1; 9-33 journals in zone 2 and 19-110 journals in zone 3 at different time period respectively. As per the Bradford distribution, these highly productive journals are top ranked. 
The degree of clustering of literature to productive journals has decreased in recent time which is visible from the nucleus zone with more number of journals. Oceanography is considerably young and multi-interdisciplinary subject and increasing number of journals in nucleus zone show the positive growth of the subject in different facets with the degree of coverage.

From the citation analysis of top 11 core journals (Deep-Sea Res, Mar Biol, Limnol Oceanogr, Mar Ecol-Prog Ser, J Phys Oceanogr, J Geophys Res-Oceans, J Exp Mar Biol Ecol, Mar Geol, Mar Chem, Estuar Coast Shelf S, Cont Shelf Res), a ranking list was generated based on the methodology followed by Gross \& Gross (1927). It is noticed that two of these journals (Mar Biol \& J Exp Mar Biol Ecol) were not covered in Fuseler-McDowell list of 21 journals (1987). When the cumulative number and percentage of articles plotted against the natural logarithm of the partial sum of the number of journals, the resulting curves are same as before, Bradford-Leimkhler curve (Fig. 4a \& $4 b)$. But the groos droop appears comparatively early with shorter straight line. Dividing the serial into a nucleus and two successive zones show nucleus consists of 3-4 journals in zone-1; 5-11 journals in zone 2 and 9-31 journals in zone 3 respectively at four different time periods. When the test of the Bradford's Law of Scattering was extended with subsequent zones, it does not satisfy beyond $4^{\text {th }}$ zone.

The decrease in clustering of literature here is asymmetrical than found earlier by complying the Bradford (1934) approach. Oceanography is a multidisciplinary subject and most likely has limited established core journals in each narrow discipline. But it is also an interdisciplinary subject which means there are number of interdisciplinary journals. So the straight line is longer in the curve when the analysis is complied Bradford method than to Gross Method.

\section{Ranking Correlation}

Fig. 4a shows that at around $100^{\text {th }}$ journal the goose drop starts. Up to $100^{\text {th }}$ rank journal the cumulative titles match between the rank lists generated by both the methods shows an increasing deviation from an ideal situation where all the titles match (Fig.5). Fig. 5 shows that at $49 \& 83$, the number of titles match are almost same in different time periods. But the percentage of matches at $49(\sim 77 \%)$ is greater than the matches at $83(\sim 70 \%)$. So the ranking correlation of top 50 journals generated in the above two methods are quite justifiable. Spearman's ranking correlations show (Table 3) better positive correlation (lowest $\rho=0.662$ for 2005-09 to highest $\rho=0.817$ for 1995-99) when top 50 ranked journals of second ranking list (generated complying Gross \& Gross approach GA) were correlated with same journal titles from first ranking list (generated complying Bradford approach - BA) than the other way (lowest $\rho=0.588$ for 2005-09 to highest $\rho=0.726$ for 1990-94). 
Table 3 also shows the trend of decrease in ranking correlation coefficient from 1990-94 to 2005-09 for both the cases.

The decrease or increase of ranking correlation coefficient depends on each and every ranking of the journals. But the better ' $\rho$-values' in the first case is due to less differences in the rankings of $\sim 23 \%$ mismatched (Fig.5) journals (between the ranking lists of BA \& GA) than in the second case. Analysis of these 23\% mismatched journals in the first ranking lists (BA) show journal titles from more sub-disciplines of Oceanography than the second ranking lists (GA). But there is not much difference in number of titles matching from both of these ranking lists with country-wise rankings (excluding three countries - Peru, Cote'd Ivory \& Kenya due to in sufficient data) of top 50 journals generated by citation analysis of articles they published (Fig. 6a-d). More than $50 \%$ of top 50 titles matched to the global ranking lists for most of the countries. Further study shows that, 28 journal titles (Table 4) of the top 50 are common in both the global rankings as well as different time periods and substantially cited. Most of these 28 journal titles are those which form major percentage of matches for different countries among top 50 ranked titles (Fig. 6a-d) and evident as primary core journals (PCJ) in the subject field of Oceanography.

During a particular time period when journals ranking correlated reciprocally ('BA to GA' and 'GA to BA'), the increase or decrease of ranking correlation coefficient depends mostly on mismatched journals. But the decrease or increase of ranking correlation coefficient from one time period to other (Table 3) in both of the above cases ('BA to GA' or 'GA to BA') depends on each and every ranking of the journals. It is also established fact that over long runs the status of the journals as well the citations to journals changes. Analysis of 28 journals (Table 4) shows there is less change in their rankings from 1990-94 to 2005-09 in Gross \& Gross approach (GA) than Bradford approach (BA). And the total differences in ranking ('BA to GA' or 'GA to BA') show increase from 1990-94 to 2005-09 leading to decrease in ranking correlation coefficient ( $\rho$-values).

\section{Conclusion}

Ranking serials by citation analysis of articles from selected source journals (Gross \& Gross 1927) or large number of articles irrespective of journals (Bradford 1934) in a subject has its importance in journal selection process in library or deciding core journals in the subject. Analysis of specialized group of journals shows a higher degree of clustering around specialized journals as well as ranking correlation favors this approach. But in a multifaceted and interdisciplinary subject field, clustering of literature to a limited number of journals can be a disadvantage. It is also showed that the mismatched journals $(\sim 23 \%)$ between the ranking lists of Gross \& Gross approach (GA) and 
Bradford approach (BA) holds the key to better ranking correlation coefficient. And these mismatched journals in the ranking lists of Bradford approach (BA) showed journal titles from more sub-disciplines of Oceanography than the other ranking lists (GA). At the same time, an equal number of matching journals from both the methods to countries-wise ranking make them equally worth to accept. In this scenario, citation analysis of a large number of articles published at national or institutional level is better choice for multi-interdisciplinary subject like 'Oceanography' in getting core journal list or rankings.

'Oceanography' as a subject has established a set of primary core journals (PCJ) which represents its multidisciplinary as well as interdisciplinary nature. The decrease in ranking correlation coefficient from one time period to other with respect to increase or decrease in ranking of these primary core journals (PCJ) in the ranking lists of Bradford approach confirms the growth of this subject at its early stage. So such studies at regional level (national or institutional level) will be very useful in understanding the alignment of the research activities in the field and planning future course of action.

During the process of investigation, the authors didn't come across any study which compares both the approach before choosing one to use in selection of journals or ranking. Although this study limits its scope to multifaceted subject field but this can be tested with other subject fields to compare the better approach in selection or ranking of journals.

\section{Acknowledgement:}

First author expresses gratitude to the Director, National Institute of Oceanography (CSIR) and Dr. M.P. Tapaswi, Documentation Officer for their encouragement and facilities provided in this academic and research endeavour. This is NIO contribution number

\section{References}

Allen, E.S. (1929). Periodicals for Mathematicians. Science, 70(1825), 592-594).

Bonitz, M. (1990). Journal ranking by different parameters. Part I. Collectivity and Selective collectivity: Two ranking parameters reflecting the structure of a journal network. Scientometries, 18(1-2), 57-73.

Bradford, S.C. (1934). Sources of information on specific subjects. Engineering, 137, 85-86.

Fuseler-Mcdowell, E. (1990). Documenting the literature of oceanography. In C.P. Winn (Ed.), Oceans from a global perspective: International cooperation in Marine Science information transfer. 
Proceedings of the 13th Annual Conference of the International Association of Marine Science Libraries and Information Centers (pp.185-204).

Gross, P.L.K. \& Gross, E.M. (1927). College libraries and Chemical Education. Science, 66(1713), 385-389.

Gross, P.L.K. \& Woodford, A.O. (1931). Serial literature used by American geologists. Science, 73(1903), 660-664.

Mabe, M. (2003). The growth and number of journals. Serials, 16(2), 191-197.

McNeely, J.K. \& Crosno, C.D. (1930). Periodicals for Electrical Engineers. Science, 72(1856), 8184.

Robert,C., Wilson, C.S., Donnadieu, S., Gaudy, J.F. \& Arreto, C.D. (2010). Evolution of the Scientific Literature on Pain from 1976 to 2007. Pain Medicine, 11(5), 670-684.

Seglen, P.O. (1997). Why the impact factor of journals should not be used for evaluating research. BJM, 314(7079), 497.

Tapaswi, M.P. \& Maheswarappa, B.S. (1999). Ranking Serials in Oceanography: An analysis based on the Indian contributions and their citations. Scientometrics, 44(1), 93-127.

Tapaswi, M.P. \& Sainekar, G.H. (1991). Methodology for continuation of Journals acquisition. Bulletin of Indian Library Association, 27, 1-7.

Vinkler, P. (1996). Relationships between the rate of scientific development and citations. The Chance for a citedness model. Scientometrics, 35(3), 375-386. 


\section{Figure Captions}

Fig. 1 Thirty coastal countries from different continents which are studied

Fig. 2 Bradford distribution at different time periods generated from the literature of thirty countries (a) Journals cited in percentage (b) Journals cited in number

Fig. 3 Rate of change in number of references per article over time

Fig. 4 Bradford distribution at different time periods generated from the articles of eleven core journals (a) Journals cited in percentage (b) Journals cited in number

Fig.5 The cumulative titles match between the rank lists generated by both the methods up to $100^{\text {th }}$ journal

Fig. 6 Number of journals matching from the country-wise ranking lists of top 50 to: the list complying GA (filled diamonds), the list complying BA (filled squares), the 28 journals which are common to all the time period and both the approaches (filled triangles) 
1 Table 1: Top 11 journals which are selected as per the number of journals in the nucleus zone of 2005-09

\begin{tabular}{lllll}
\hline $\begin{array}{l}\text { SI. } \\
\text { No. }\end{array}$ & 1990-94 & $1995-99$ & $2000-04$ & $2005-09$ \\
\hline 1 & NATURE & NATURE & NATURE & MAR ECOL-PROG SER \\
2 & MAR BIOL & MAR ECOL-PROG SER & MAR ECOL-PROG SER & NATURE \\
3 & DEEP-SEA RES & LIMNOL OCEANOGR & J GEOPHYS RES-OCEANS & SCIENCE \\
4 & LIMNOL OCEANOGR & MAR BIOL & LIMNOL OCEANOGR & J GEOPHYS RES-OCEANS \\
5 & MAR ECOL-PROG SER & J GEOPHYS RES-OCEANS & J PHYS OCEANOGR & LIMNOL OCEANOGR \\
6 & & SCIENCE & GEOPHYS RES LETT \\
7 & & MAR BIOL & EARTH PLANET SC LETT \\
8 & & GEOCHIM COSMOCHIM AC & \\
9 & & EARTH PLANET SC LETT & \\
10 & & J GEOPHYS RES & \\
11 & & DEEP-SEA RES & \\
\hline
\end{tabular}


Table -2: Form-wise and source-wise distribution of citations

\begin{tabular}{lllll}
\hline & Form-wise & & Source-wise \\
Years & Serial articles & Other items & Serial titles & Other titles \\
\hline 1990 to 94 & 147588 & 37696 & 16035 & 19349 \\
& $(79.66 \%)$ & $(20.44 \%)$ & $(45.32 \%)$ & $(54.68 \%)$ \\
1995 to 99 & 259427 & 64762 & 22545 & 31023 \\
& $(80.02 \%)$ & $(19.98 \%)$ & $(42.09 \%)$ & $(57.91 \%)$ \\
2000 to 04 & 399059 & 84463 & 28205 & 39794 \\
& $(82.53 \%)$ & $(17.47 \%)$ & $(41.48 \%)$ & $(58.52 \%)$ \\
2005 to 09 & 659027 & 114561 & 38969 & 55108 \\
& $(85.19 \%)$ & $(14.81 \%)$ & $(41.42 \%)$ & $(58.58 \%)$ \\
\hline
\end{tabular}

Table -3: Spearman's ranking correlation coefficient $(\rho)$ reciprocally between the rank lists generated complying Bradford Approach (BA) and Gross \& Gross Approach (GA)

\begin{tabular}{lllll}
\hline Correlation & $1990-1994$ & $1995-1999$ & $2000-2004$ & $2005-2009$ \\
\hline BA to GA & 0.809 & 0.817 & 0.758 & 0.662 \\
GA to BA & 0.726 & 0.711 & 0.703 & 0.588 \\
\hline
\end{tabular}


Table 4: Serials in the top 50 cited list which are common to both the global rankings as well as different time periods and their percentage

\begin{tabular}{|c|c|c|c|c|c|c|c|c|c|}
\hline \multirow[b]{2}{*}{ S1. No. } & \multirow[b]{2}{*}{ Title } & \multicolumn{4}{|c|}{ Bradford approach } & \multicolumn{4}{|c|}{ Gross \& Gross approach } \\
\hline & & $90-94$ & $95-99$ & $00-04$ & 05-09 & $90-94$ & $95-99$ & $00-04$ & 05-09 \\
\hline 1 & APPL ENVIRON MICROB & 0.56 & 0.59 & 0.80 & 0.92 & 0.90 & 0.62 & 0.51 & 0.54 \\
\hline 2 & CAN J FISH AQUAT SCI & 1.05 & 0.87 & 0.70 & 0.63 & 0.97 & 0.93 & 0.89 & 0.94 \\
\hline 3 & CONT SHELF RES & 0.32 & 0.45 & 0.47 & 0.55 & 0.70 & 0.83 & 1.10 & 1.30 \\
\hline 4 & DEEP-SEA RES+ & 2.36 & 2.55 & 2.62 & 2.38 & 4.15 & 4.51 & 5.01 & 4.11 \\
\hline 5 & EARTH PLANET SC LETT & 1.59 & 1.30 & 1.32 & 1.29 & 0.59 & 0.48 & 0.41 & 0.36 \\
\hline 6 & ECOLOGY & 0.46 & 0.40 & 0.43 & 0.50 & 1.15 & 1.11 & 1.07 & 1.31 \\
\hline 7 & ENVIRON SCI TECHNOL & 0.29 & 0.37 & 0.55 & 0.71 & 0.31 & 0.34 & 0.36 & 0.33 \\
\hline 8 & ESTUAR COAST SHELF S & 0.41 & 0.53 & 0.52 & 0.65 & 0.79 & 0.86 & 1.06 & 1.57 \\
\hline 9 & GEOCHIM COSMOCHIM AC & 1.51 & 1.45 & 1.38 & 1.15 & 1.25 & 1.17 & 1.05 & 0.91 \\
\hline 10 & GEOPHYS RES LETT & 0.31 & 0.43 & 0.88 & 1.43 & 0.23 & 0.37 & 0.76 & 1.36 \\
\hline 11 & HYDROBIOLOGIA & 0.50 & 0.48 & 0.46 & 0.47 & 0.57 & 0.59 & 0.71 & 0.87 \\
\hline 12 & J EXP MAR BIOL ECOL & 1.08 & 1.03 & 0.97 & 0.87 & 2.79 & 2.56 & 2.45 & 2.48 \\
\hline 13 & J FISH BIOL & 0.38 & 0.41 & 0.35 & 0.34 & 0.23 & 0.27 & 0.36 & 0.46 \\
\hline 14 & J GEOPHYS RES+ & 4.08 & 4.22 & 4.39 & 3.69 & 5.72 & 6.33 & 5.81 & 4.82 \\
\hline 15 & J MAR BIOL ASSOC UK & 0.64 & 0.51 & 0.39 & 0.33 & 0.90 & 0.81 & 0.72 & 0.65 \\
\hline 16 & J MAR RES & 0.84 & 0.66 & 0.53 & 0.32 & 1.55 & 1.34 & 1.05 & 0.74 \\
\hline 17 & J PHYCOL & 0.57 & 0.60 & 0.48 & 0.46 & 0.67 & 0.65 & 0.65 & 0.53 \\
\hline 18 & J PHYS OCEANOGR & 2.02 & 1.75 & 1.68 & 1.18 & 4.17 & 4.50 & 4.00 & 3.01 \\
\hline 19 & J PLANKTON RES & 0.62 & 0.63 & 0.56 & 0.44 & 0.94 & 0.96 & 0.91 & 0.79 \\
\hline 20 & LIMNOL OCEANOGR & 2.06 & 1.94 & 1.75 & 1.47 & 4.77 & 4.61 & 4.21 & 3.83 \\
\hline 21 & MAR BIOL & 2.34 & 1.85 & 1.42 & 1.13 & 4.43 & 3.76 & 3.17 & 2.84 \\
\hline 22 & MAR CHEM & 0.47 & 0.79 & 0.68 & 0.59 & 0.98 & 1.19 & 1.19 & 1.12 \\
\hline 23 & MAR ECOL-PROG SER & 2.03 & 2.55 & 2.59 & 2.42 & 4.34 & 5.36 & 5.93 & 6.47 \\
\hline 24 & MAR GEOL & 0.81 & 0.76 & 0.74 & 0.74 & 1.01 & 0.88 & 1.21 & 1.22 \\
\hline 25 & NATURE & 2.84 & 2.86 & 2.69 & 2.40 & 2.47 & 2.56 & 2.56 & 2.20 \\
\hline 26 & POLAR BIOL & 0.28 & 0.38 & 0.35 & 0.27 & 0.35 & 0.37 & 0.50 & 0.43 \\
\hline 27 & PROG OCEANOGR & 0.26 & 0.29 & 0.39 & 0.38 & 0.39 & 0.53 & 0.72 & 0.81 \\
\hline \multirow[t]{2}{*}{28} & SCIENCE & 1.29 & 1.32 & 1.54 & 1.81 & 1.63 & 1.58 & 1.54 & 1.75 \\
\hline & Total & 31.97 & 31.97 & 31.63 & 29.52 & 48.95 & 50.07 & 49.91 & 47.75 \\
\hline
\end{tabular}


Figure 1

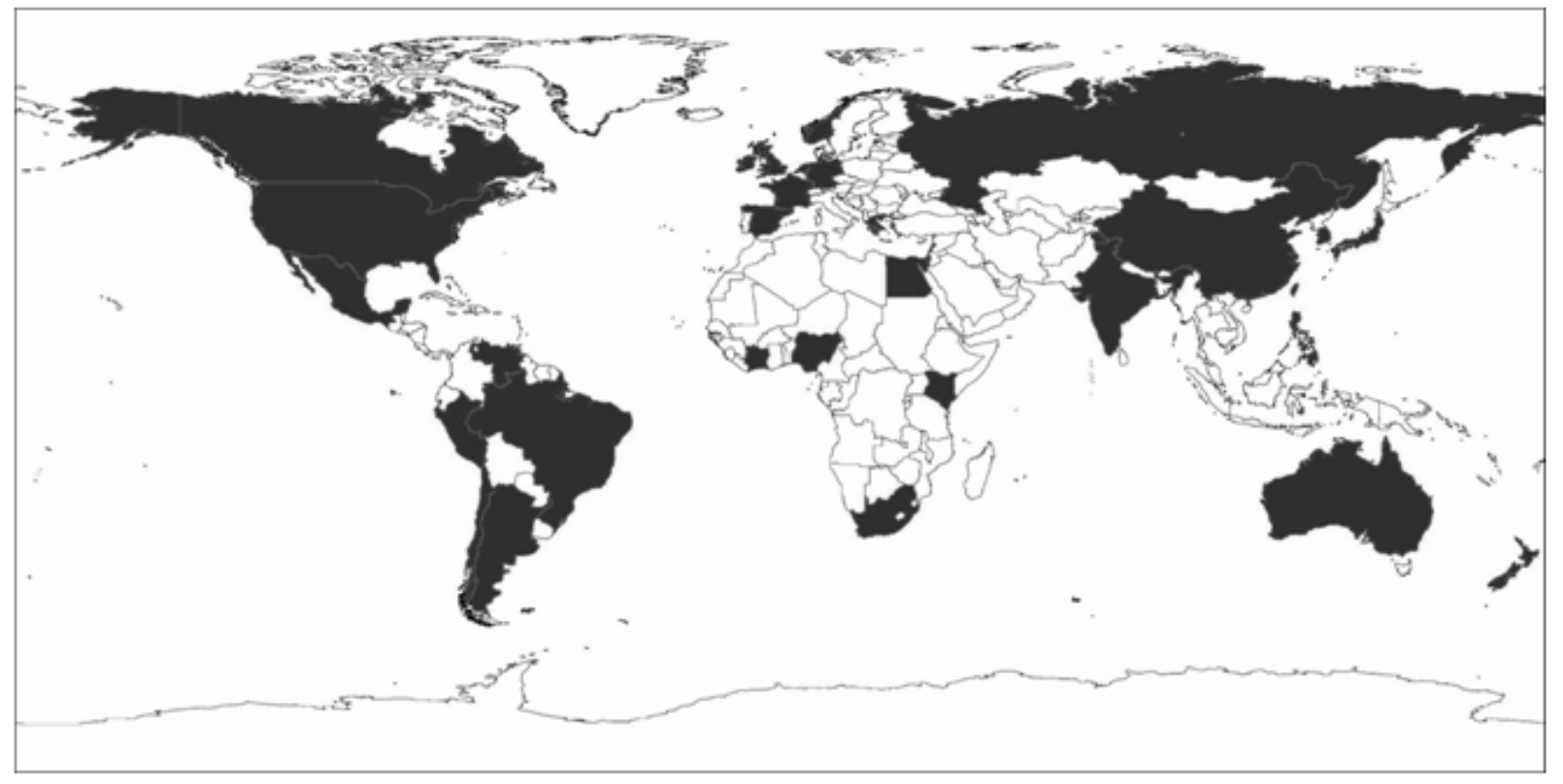

Figure 2
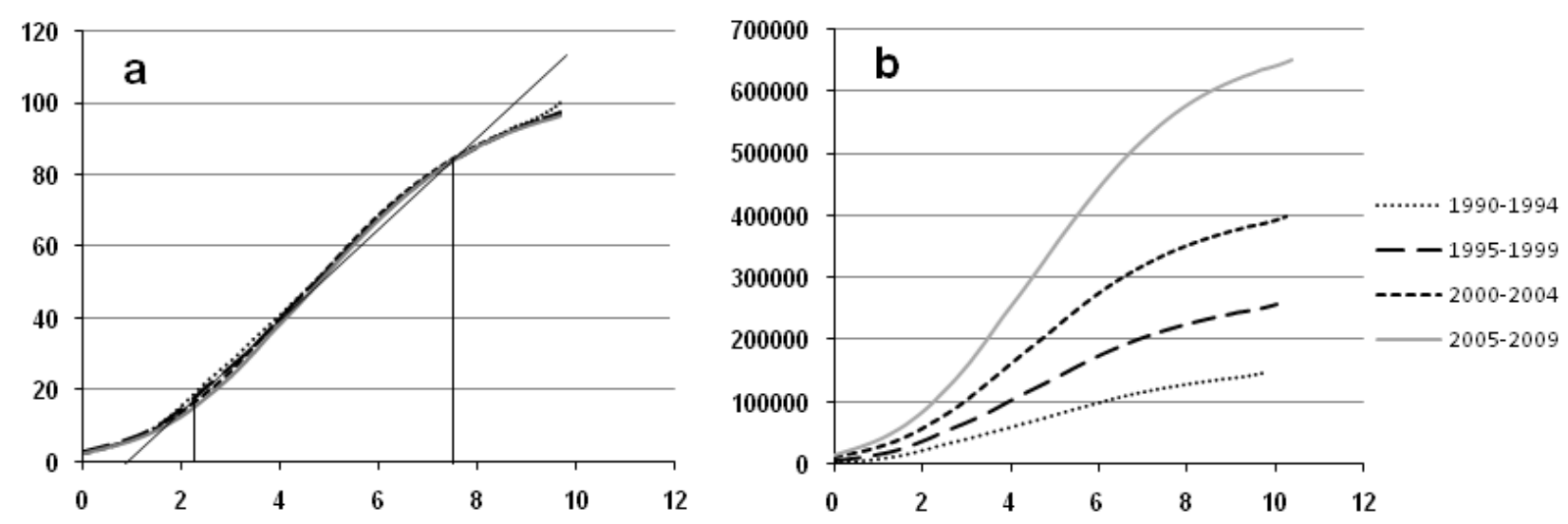
Figure 3

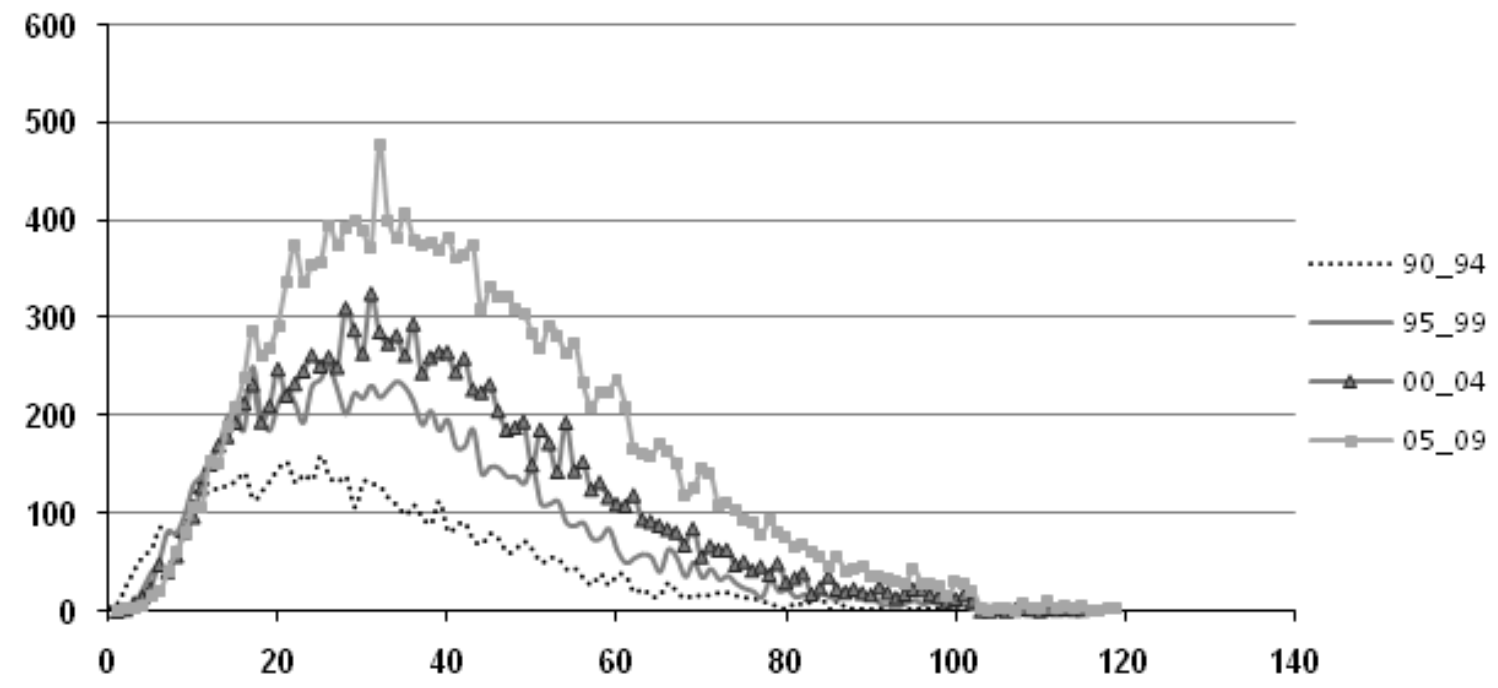

Figure 4
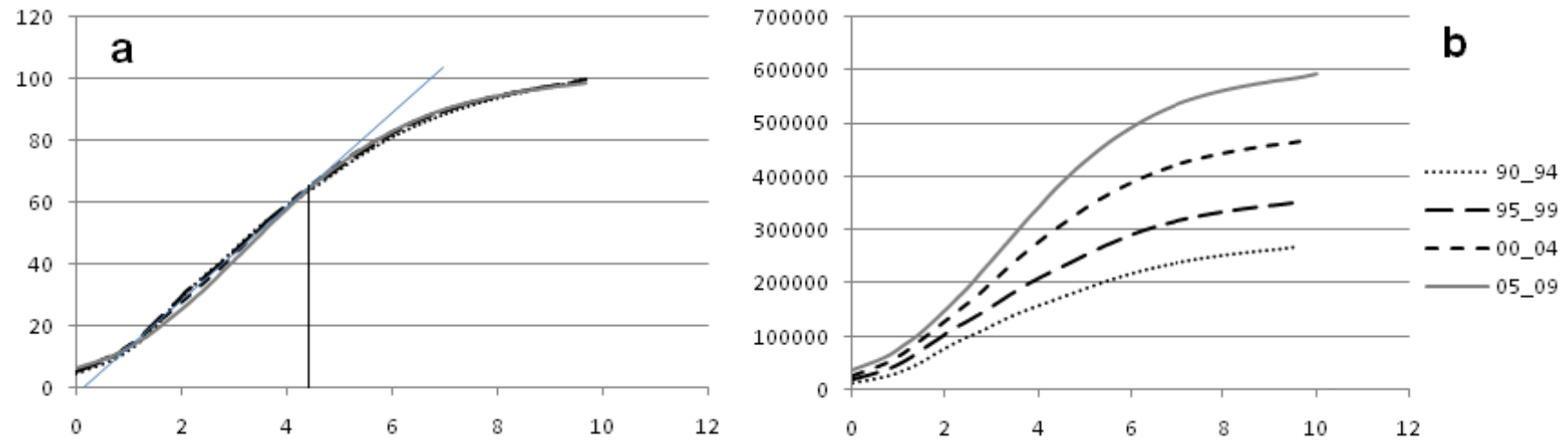
Figure 5

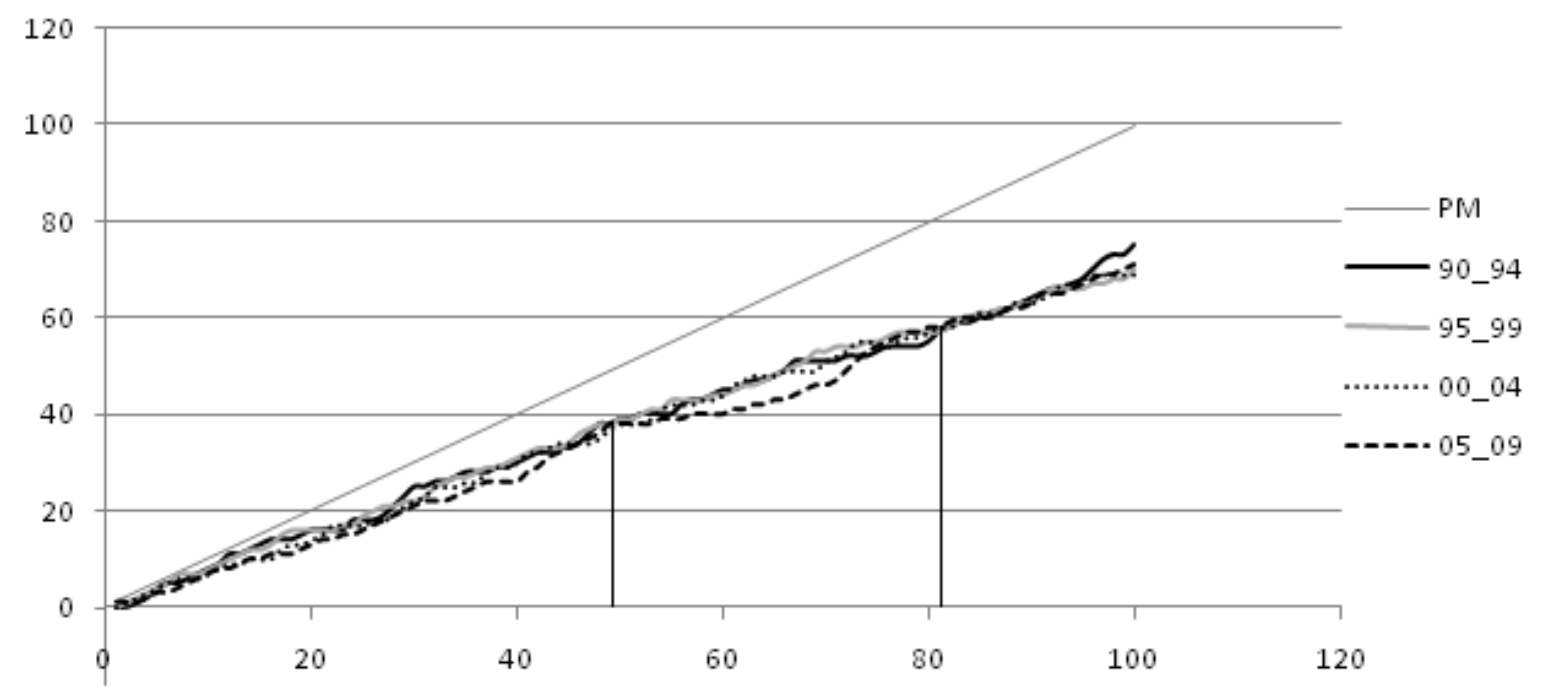

Figure 6
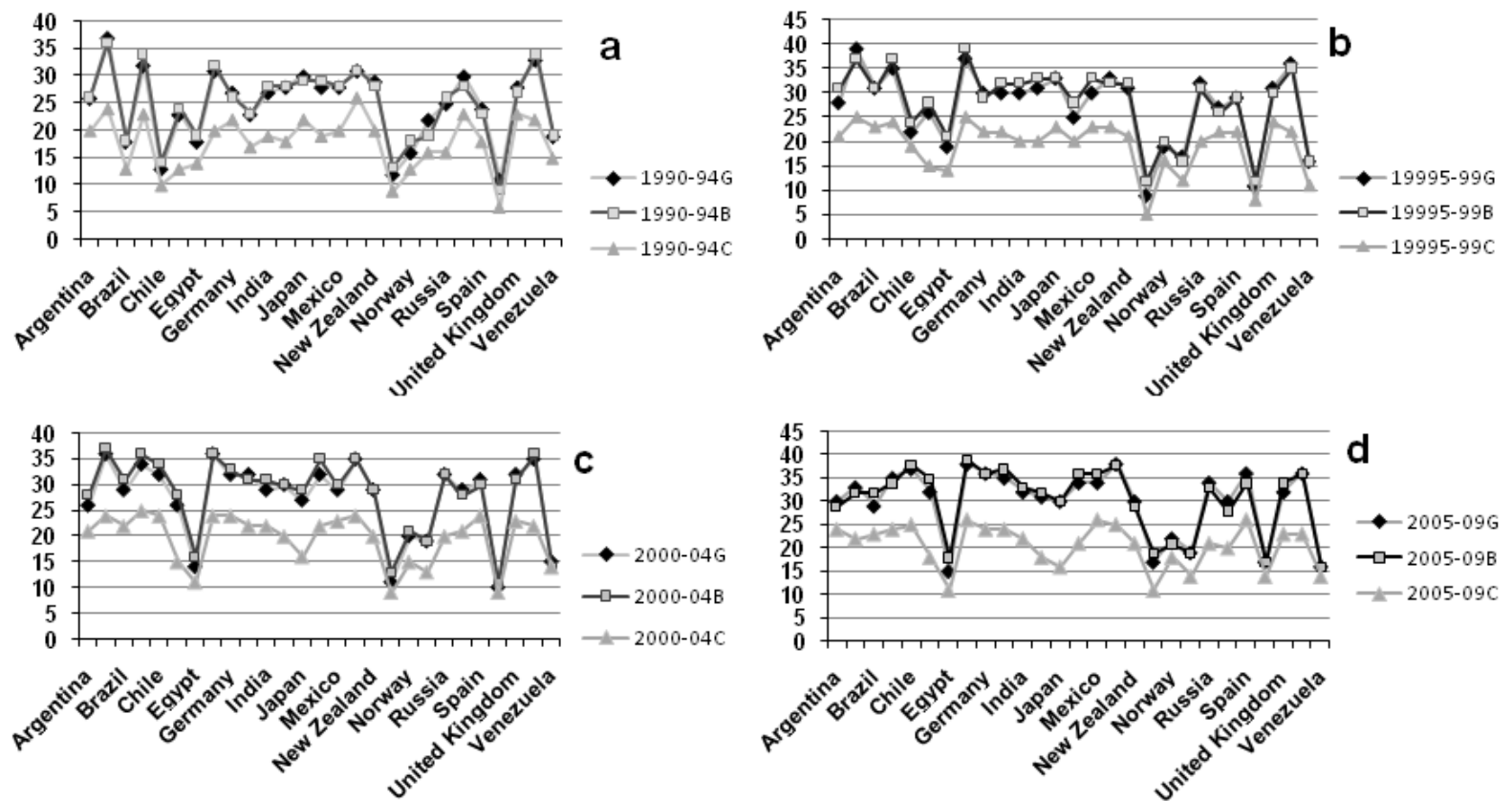